Journal of Management

Vol. XX No. X, Month XXXX 1-24

DOI: $10.1177 / 0149206316672532$

(C) The Author(s) 2016

Reprints and permissions:

sagepub.com/journalsPermissions.nav

\title{
Delighting the Customer: Creativity-Oriented High-Performance Work Systems, Frontline Employee Creative Performance, and Customer Satisfaction
}

\author{
Ieva Martinaityte \\ University of East Anglia \\ Claudia Sacramento \\ Aston University \\ Samuel Aryee \\ King's College London
}

\begin{abstract}
Drawing on self-determination theory, we proposed and tested a cross-level model of how perceived creativity-oriented high-performance work systems (HPWS) influence customer satisfaction. Data were obtained from frontline employees (FLEs), their managers, and branch records of two organizations (retail bank and cosmetics) in Lithuania. Results of multilevel structural equation modeling analyses revealed partial support for our model. Although perceived creativity-oriented HPWS related to creative performance at the individual level, this effect was mediated solely by need satisfaction and not by creative process engagement nor by a serial mediation of both variables as we hypothesized. However, as we did hypothesize, average branch creative performance related to branch customer satisfaction. We interpret our findings as underscoring the utility of perceived creativity-oriented HPWS in fostering FLEs' creative performance and ultimately, customer satisfaction.
\end{abstract}

Keywords: perceived creativity-oriented high-performance work systems; self-determination theory; psychological need satisfaction; creative process engagement; creative performance; customer satisfaction

Acknowledgments: We acknowledge the editor and three anonymous reviewers for their feedback and encouragement. Supplemental material for this article is available at http://jom.sagepub.com/supplemental

Corresponding author: Samuel Aryee, King's College London, School of Management and Business, 150 Stamford St., London SE1 9NH, UK.

E-mail: samuel.aryeee@kcl.ac.uk 
The very nature of service exchanges provides FLEs with a real-time dilemma that often requires non-traditional thinking to resolve. ... To alter the service performance, FLEs often need to hone critical thinking skills to creatively determine viable options to address unique customer needs.

—Wilder, Collier, and Barnes (2014: 448)

To adapt to and survive in an increasingly dynamic and competitive global marketplace, service organizations have embraced a service excellence strategy (Schneider \& White, 2004). Underpinning this strategy is a recognition of the importance of adapting the service delivery to meet the diverse and unique needs of customers as a way to enhance such customer-related outcomes as customer satisfaction and retention and, thus, organizational performance (Gwinner, Bitner, Brown, \& Kumar, 2005; Wilder, Collier, \& Barnes, 2014). Given the criticality of frontline employees (FLEs) in the implementation of a service excellence strategy, much research effort has been invested in understanding the motivational basis of FLEs' service delivery behaviors (Chuang \& Liao, 2010; Hong, Liao, Hu, \& Jiang, 2013). A dynamic marketplace in which customers have diverse and unique needs suggests that service organizations must temper their previous focus on prescribed or scripted behaviors in the service delivery process (appropriate in a stable, undifferentiated marketplace) with a focus on unscripted or adaptive behaviors. Critical to these adaptive behaviors is FLEs' creative performance, which, in a service context, describes not only the extent of new ideas generated and novel behaviors that FLEs exhibit in performing their service delivery role (Wang \& Netemeyer, 2004) but also the adaption or customization of existing ideas to meet the unique needs of customers (Madjar \& Ortiz-Walters, 2008).

Despite the potential influence of FLEs' creative performance on customer outcomes and, ultimately, organizational performance (Coelho, Augusto, \& Lages, 2011: 32), creative performance in frontline service roles (Dong, Liao, Chuang, Zhou, \& Campbell, 2015; Gilson, Mathieu, Shalley, \& Ruddy, 2005; Madjar \& Ortiz-Walters, 2008) has not received much research attention relative to the organizational literature on creative performance. While the extant research has shown individual and contextual factors as well as their interactions (Amabile, 1996; Zhou \& Hoever, 2014) to relate to creative performance, neither the influence of human resource practices on creative performance nor the influence of creative performance on operational outcomes has witnessed much empirical research in service contexts (for exceptions, see Agnihotri, Rapp, Andzulis, \& Gabler, 2014; Dong et al., 2015; Gilson et al., 2005). Consequently, researchers may be overlooking an opportunity to develop the knowledge base to help service organizations develop a strategic capability to implement their service excellence strategy and thereby create and sustain competitive advantage.

To signal the importance of such an undertaking, Shalley and Gilson (2004) suggested that practices used to select, train, appraise, and reward employees must be systematically linked to synergistically influence creative performance. This dovetails with research in strategic human resource management (SHRM) that has focused on bundles of human resource (HR) practices and their influence on organizational outcomes (Applebaum, Bailey, Berg, \& Kalleberg, 2000; Jiang, Lepak, Hu, \& Baer, 2012). Implicit in Shalley and Gilson's (2004) suggestion is a call to develop bundles of HR practices oriented to an organization's strategic focus of using creative performance as a strategic capability to achieve service excellence and, ultimately, sustained competitive advantage. Building on research (Chang, Jia, Takeuchi, 
\& Cai, 2014; Liu, Gong, Zhou, \& Huang, in press) that has since responded to Shalley and Gilson's (2004) call and informed by SHRM theorizing on how an HR system-for example, high-performance work systems (HPWS) _ operates (D. E. Bowen \& Ostroff, 2004), we proposed and tested a cross-level model of the processes through which perceived creativityoriented HPWS promotes FLEs' creative performance that in turn leads to unit-level customer satisfaction. Specifically, we drew on self-determination theory (SDT) to examine need satisfaction and creative process engagement as pathways through which perceived creativity-oriented HPWS influences creative performance. Furthermore, we examined at the unit level the influence of average branch creative performance on unit-level (branch) customer satisfaction.

By examining these cross-level linkages, our study contributes to the HPWS and creativity literatures in two significant ways. First, we extend prior research by examining SDTinformed multiple pathways through which perceived creativity-oriented HPWS influences creative performance. For example, Marescaux, Winne, and Sels (2013) examined need satisfaction as a pathway through which perceived HPWS influences the employee work outcomes of organizational commitment and turnover intentions. Furthermore, prior HPWS research only invoked need satisfaction as an explanatory construct but did not examine its mediating role in the relationships examined (Gardner, Wright, \& Moynihan, 2011). Although need satisfaction occupies a central role in SDT (Deci \& Ryan, 2000) and has been suggested to constitute a proximal antecedent of autonomous motivation and, ultimately, work outcomes (Vallerand, 2000), prior SDT-grounded HPWS research has not fully examined these mediating mechanisms. Given the potential of SDT as an alternative explanatory framework to the predominantly social exchange framework in HPWS research (Liao, Toya, Lepak, \& Hong, 2009; Sun, Aryee, \& Law, 2007; Takeuchi, Lepak, Wang, \& Takeuchi, 2007), it is important that HPWS research provides a more complete test of the postulates of SDT.

Second, although creative performance has been theorized to influence customer satisfaction and, ultimately, organizational performance (Coelho et al., 2011), there is a paucity of research that has examined the influence of unit (average) creative performance on customerrelated outcomes. While Sung and Choi (2012) reported unit creative performance to relate to unit financial performance in a service context, financial performance is a distal outcome that is dependent on customer or operational outcomes (Hong et al., 2013). Furthermore, although Wilder and colleagues (2014) conceptualized creative performance as a component of adaptive service delivery, they did not examine its customer-related outcomes. Thus, our study not only extends Wilder and colleagues' model of adaptive service delivery by examining customer satisfaction as an outcome of creative performance but also provides a more rigorous test of this relationship. The reason is that, unlike prior research (Dong et al., 2015; Gilson et al., 2005), we collected customer satisfaction data 6 months (two quarters) after the collection of data on creative performance, and we controlled for level of customer satisfaction in the 6 months (two quarters) preceding our survey.

\section{Theoretical Framework and Hypotheses Development}

SDT draws on the long tradition of need-based theories of motivation to explicate the motivational underpinnings of human behavior and well-being. However, unlike previous need-based theories of motivation (Maslow, 1954; White, 1959) that conceived of needs as 
any desire, goal, or want, SDT considers needs as "innate, essential, and universal" (Ryan \& Deci, 2000: 74). Deci and Ryan (2000: 229) therefore noted that "needs specify innate psychological nutriments that are essential for ongoing psychological growth, integrity, and well-being." SDT delineates three universal needs: autonomy (a need to exercise control over one's actions in accordance with one's integrated sense of self), competence (a need to have an effect on one's outcomes), and relatedness (a need to feel connected and mutual respect with others). Although needs are considered to be universal, the extent of need satisfaction varies across individuals, leading to variance in individual outcomes. While the three needs have been shown to be conceptually distinct, they operate synergistically to promote effective human functioning and are therefore operationalized as overall psychological need satisfaction (Lian, Ferris, \& Brown, 2012). As need satisfaction promotes self-regulation and effective functioning, SDT and its central construct of need satisfaction have been employed as a motivational framework to account for work-related behaviors and psychological wellbeing (Gagné \& Deci, 2005; Greguras \& Diefendorff, 2009).

Although myriad theoretically informed variables, such as social exchange-based constructs (Takeuchi et al., 2007), have been employed to account for the performance effects of HPWS, we focused this study on SDT. The reason is that, as a self-determined behavior, FLEs' creative performance is fostered by the autonomous motivation inherent in SDT, which enables FLEs to seek novel or customize existing ideas to meet the needs and expectations of customers. The effectiveness of these solutions depend not only on the skills and competencies of FLEs (domain- and creativity-relevant skills) but also on their motivation to leverage these skills to provide solutions to customer needs and expectations. As we argue in the next section, the componential model of creativity (Amabile, 1996) that underpins our measure of perceived creativity-oriented HPWS constitutes a social environment that provides the nutriments to satisfy employee psychological needs, thereby fostering creative process engagement leading to FLEs' creative performance.

We posit perceived creativity-oriented HPWS as influencing need satisfaction and creative process engagement, a dual-pathway through which HPWS influences creative performance. Given the centrality of self-determined motivation to SDT, we also posit need satisfaction to indirectly relate to creative performance through creative process engagement. In line with the notion that HPWS engenders behaviors and attitudes that promote organizational performance (D. E. Bowen \& Ostroff, 2004), we considered individual-level creative behavior as a unit-level construct - namely, branch average creative performance - and examined its influence on branch customer satisfaction (see online supplement for the figure reflecting our modeling of the individual- and group-level variance existent in these measures; Preacher, Zyphur, \& Zhang, 2010).

\section{Perceived Creativity-Oriented HPWS}

Following the observation that HR systems must be driven by an organization's strategic goals and values, the bundles of HR practices used in this stream of research are increasingly "designed around a particular strategic focus, such as service or innovation" (D. E. Bowen \& Ostroff, 2004: 206). Consequently, recognition of service excellence as a competitive strategy necessitates adopting bundles of HR practices with the overriding objective of developing and leveraging the capability of FLEs to deliver high-quality service. The nature of the service delivery (involving customer coproduction of the service, intangibility, and 
heterogeneity) coupled with the importance of adapting the service delivery to the needs and expectations of customers requires FLEs to be creative to customize the service delivery. Thus, a creativity-oriented HPWS describes a system of interrelated HR practices designed to enhance employees' competencies, motivation, and opportunity for creative performance.

Given that frontline service roles are shaped by the needs and expectations of customers, effective performance in these roles requires an ability to customize the service delivery to meet these needs and expectations (Agnihotri et al., 2014). Accordingly, this requires FLEs to "think outside of the box," thereby making Amabile's (1996) componential model appropriate for identifying HR practices that foster the model's components of domain-relevant skills (job-specific knowledge and skills), creativity-relevant skills (ability to think outside of the box), and task motivation (self-regulation in the performance of a task). Drawing on this model, we identified an initial set of HR practices that are germane to developing, motivating, and providing opportunities for the use of skills that enable FLEs to creatively adapt the service delivery to the needs and expectations of customers. We focused on selective hiring, extensive training, performance appraisal, and compensation because they have implications for domain- and creativity-relevant skills (Chang et al., 2014). We also included employee participation and information sharing, as they have implications for intrinsic motivation.

Although the creativity-oriented HPWS used in this context shares the same conceptual space as Liao and colleagues' (2009) HPWS for service quality, they differ in one key respect. As Gilson and colleagues (2005) reported, service quality and, ultimately, customer satisfaction can be achieved through the use of standardized or scripted work behaviors. However, FLEs' ability to customize the service delivery to meet the idiosyncratic needs and expectations of customers provides an opportunity to pleasantly surprise or delight customers, leading to enhanced levels of customer satisfaction (Dong et al., 2015). Thus, our focus on creativity-oriented HPWS signals the extent to which FLEs perceive an organization's emphasis on creative performance or customization of the service delivery as a strategic behavior in promoting service quality. Indeed, customization has been noted to be an important criterion of service quality (Hong, Liao, Sturman, \& Zhou, 2014). In this respect, the intent of creativity-oriented HPWS is similar to other strategically focused HPWSs, such as HPWS for knowledge-intensive teamwork (Chuang, Jackson, \& Jiang, 2016) and initiativeenhancing HPWS (Hong, Liao, Raub, \& Han, 2016).

\section{Perceived Creativity-Oriented HPWS, Need Satisfaction, and Creative Process Engagement}

We focused on perceived rather than manager-rated creativity-oriented HPWS because it defines the social environment in which employees operate and is therefore more proximal to their work-related attitudes and behaviors (Aryee, Walumbwa, Seidu, \& Otaye, 2012; Kehoe \& Wright, 2013; Liao et al., 2009). The constituent practices that define the skill component of perceived creativity-oriented HPWS, such as extensive training, performance feedback, and selection, should enhance both domain- and creativity-relevant skills, thereby satisfying an FLE's competency need. Furthermore, such practices as delegation of decisionmaking authority and the inherent opportunities to experience discretion will foster creativity-relevant skills, thus satisfying their autonomy need. The components of participation and information sharing, extensive and broad training, and job design that provide opportunities 
to interact at work will enhance task motivation as well as signal cues about one's acceptance as an organizational member, therefore satisfying their relatedness need (Sheldon, Turban, Brown, Barrick, \& Judge, 2003). As these practices operate synergistically, they provide the nutriments that satisfy these three psychological needs. Although Gardner and colleagues (2011) did not empirically test these relationships drawing on SDT, they did theorize the skill-, motivation-, and empowerment-enhancing components of HPWS to relate to need satisfaction. In support of these arguments, Marescaux and colleagues (2013) reported the individual HR practices that they examined to relate to satisfaction of need for autonomy, competence, and relatedness. Accordingly, we hypothesize the following:

Hypothesis 1: Perceived creativity-oriented HPWS positively relates to need satisfaction.

Drawing on the extant research (Amabile, 1983; Zhang \& Bartol, 2010), we defined creative process engagement as "an employee involvement or engagement in creativity-relevant cognitive processes that entail (a) problem identification, (b) information searching and encoding, and (c) idea and alternative generation" (Zhang \& Bartol, 2010: 112). Perceived creativity-oriented HPWS promotes a context in which employees not only develop the domain- and creativity-relevant skills but also the motivation and discretion to engage in search processes enabling them to customize the service offering to meet the needs of customers (cf. Chang et al., 2014). For instance, if employees participate in creativity training, it will increase their awareness of creative processes and enhance their skills by learning new methods and tools for idea generation and development. Information sharing and participation in decision-making practices will provide socialization opportunities during which FLEs can discuss customer-related problems and acquire customer need knowledge, thereby motivating the development of customized solutions to the needs and expectations of customers through creative process engagement. Although prior research has not directly examined the influence of perceived creativity-oriented HPWS on creative process engagement, there is much indirect support for this relationship. For example, research has shown perceived HPWS to relate to psychological empowerment (Aryee et al., 2012; Liao et al, 2009), which in turn has been shown to relate to creative process engagement (Zhang \& Bartol, 2010). Furthermore, Gilson and Shalley (2004) reported creativity-supportive climate, task design, and team member interactions (conceptually similar to the components of perceived creativity-oriented HPWS) to relate to creative process engagement. Thus, we posit perceived creativity-oriented HPWS to relate to creative process engagement.

Hypothesis 2: Perceived creativity-oriented HPWS positively relates to creative process engagement.

Creative process engagement reflects a form of autonomous regulation that, according to SDT, is made possible through need satisfaction (Deci \& Ryan, 2000). Implicit in FLEs' autonomy need satisfaction is the acquisition of domain-relevant skills, including customer need knowledge. This enables FLEs to understand what customers care about and the discretion to engage in a search or creative process to obtain solutions to customize the service offering. Similarly, the satisfaction of competence need suggests acquisition of domain- and creativity-relevant skills that FLEs can use to identify latent customer problems, search for information related to these problems, and develop alternative solutions to satisfy customer needs. Relatedness need satisfaction imbues FLEs with a sense of responsibility for the 
well-being of the organization and a sense of meaning from their role. Collectively, these attributes motivate FLEs to exchange information on customers' problems with the team and obtain the different perspectives necessary to generate solutions to emergent customer needs. Although prior research has not examined the need satisfaction-creative process engagement relationship, need satisfaction has been theorized (Deci \& Ryan, 2000; Gagné \& Deci, 2005) as well as empirically reported to relate to intrinsic motivation (Aryee, Walumbwa, Mondejar, \& Chu, 2015; Van den Broeck, Vansteenkiste, de Witte, Soenens, \& Lens, 2010), which has been shown to relate to creative process engagement (Zhang \& Bartol, 2010). Since these needs operate synergistically, we expect them to foster the autonomous motivation that engenders creative process engagement:

Hypothesis 3: Need satisfaction positively relates to creative process engagement.

\section{Need Satisfaction, Creative Process Engagement, and Creative Performance}

As previously noted, we examined need satisfaction and creative process engagement as related but alternative pathways through which perceived creativity-oriented HPWS relates to creative performance. Inherent in competence satisfaction is the belief that one has the ability to customize the service delivery to meet the idiosyncratic needs of customers, leading to creative performance. Furthermore, FLEs will be motivated to customize the service delivery to the needs and expectations of the customer if they have the autonomy to deviate from the scripted service behavior. The uncertainty inherent in deviating from the service script makes the adaptation and/or customization of the service to the needs of the customer a rather risky undertaking. However, the trust inherent in feeling a sense of belonging will mitigate this risk, thereby motivating FLEs to adapt the service delivery to the needs of the customer, leading to creative performance. As previously noted, implicit in need satisfaction are domain- and creativity-relevant skills, which have been shown to relate to creativity (Agnihotri et al., 2014; Liu et al., in press), as have work-related interactions (belongingness need) and the resulting exchange of information (Perry-Smith, 2006). Accordingly, we expect need satisfaction to relate to creative performance:

Hypothesis 4: Need satisfaction positively relates to creative performance.

Creative process engagement reflects the creativity-relevant processes that "determine the flexibility with which cognitive pathways are explored, the attention given to particular aspects of the task, and the extent to which a particular pathway is followed in pursuit of a solution" (Amabile, 1996: 95). Customers' unique needs constitute an input into the creative process that motivates FLEs to draw on their customer need knowledge or domain-relevant skills to engage in a search process. Consequently, FLEs immerse themselves in understanding the problem from different perspectives, obtain information from diverse sources, and generate creative and novel solutions to customize the service delivery to meet the customer's needs and expectations. Creative process engagement has since been reported to relate to individual creative performance (Huang, Krasikova, \& Liu, 2016; Zhang \& Bartol, 2010). Accordingly, we hypothesize the following:

Hypothesis 5: Creative process engagement positively relates to creative performance. 


\section{Mediation Hypotheses}

Although prior research has reported a generic HPWS to relate to creative performance (Chang et al., 2014; Liu et al., in press), we are drawing on SDT and so expect creativityoriented HPWS to relate to creative performance but indirectly, through need satisfaction and creative process engagement. Accordingly, our arguments in the preceding sections - that (a) perceived creativity-oriented HPWS relates to both need satisfaction and creative process engagement, (b) need satisfaction relates to creative process engagement, and (c) need satisfaction and creative process engagement relate to creative performance - suggest three mediated hypotheses:

Hypothesis 6: Perceived creativity-oriented HPWS positively relates to employee creative performance through the serial mediating mechanisms of need satisfaction and creative process engagement.

Hypothesis 7: Need satisfaction mediates the relationship between perceived creativity-oriented HPWS and creative performance.

Hypothesis 8: Creative process engagement mediates the relationship between perceived creativityoriented HPWS and creative performance.

\section{Branch-Level Average Creative Performance and Branch Customer Satisfaction}

Satisfied customers have been reported to have a high retention rate (Towler, Lezotte, \& Burke, 2011) and generate high sales volumes (Ahearne, Mathieu, \& Rapp, 2005). In light of these bottom-line implications, customer satisfaction is considered an important indicator of a service organization's performance. The extant research on the antecedents of customer satisfaction - defined as "a pleasurable level of consumption-related fulfilment" (Oliver, 1977: 13) - has focused on the attitudes and service behaviors of FLEs (Ahearne et al., 2005). Indeed, J. Bowen and Ford (2002: 451) noted that "the intangibility of the service product means that the organization must seek to identify the driving force behind customers' purchase of the service and compete on the degree to which its particular service meets or exceeds those expectations."

As prior research has examined the influence of creative performance on customer satisfaction at the individual level (Dong et al., 2015), we focused on the unit/branch level in this study (Gilson et al., 2005) because it is at this level that creative performance can be leveraged to enhance customer satisfaction and its financial outcomes. FLEs' adoption of a problemsolving approach in their interactions with customers entails devising a novel or adapting an existing process or procedure to customize the service offering. However, as customers expect at a minimum to be satisfied (Arnold, Reynolds, Ponder, \& Lueg, 2005), FLEs' novel or adaptive service delivery must elicit, on the part of the customer, a pleasant surprise stemming from overmet needs and expectations, leading to satisfaction with the service delivery experience (Barnes, Beauchamp, \& Webster, 2010). As customers are unlikely to interact with the same FLE, fostering unit/branch-level customer satisfaction would require that creative performance becomes an attribute of the unit/branch and, therefore, an organizational capability, which can be leveraged to exceed the expectations of customers (Liao et al., 2009; Raub \& Liao, 2012). In support of our reasoning, prior research has shown FLEs' customer-related 
behaviors or service-oriented organizational citizenship behaviors to relate to customer satisfaction (Ahearne et al., 2005; Dong et al., 2015; Gilson et al., 2005; Hong et al., 2013; Liao et al., 2009; Raub \& Liao, 2012). Therefore, we propose,

Hypothesis 9: Average branch creative performance positively relates to branch customer satisfaction.

\section{Method}

\section{Sample and Procedure}

Data for this study were obtained from FLEs and their branch managers, who were employed in 53 branches (units) of two international companies operating in retail banking (31 branches) and cosmetics (22 branches) in Lithuania. Initial contact with the participating organizations was made via a phone call to their respective HR directors, during which the objectives of the study and data collection procedures were discussed. The HR directors then communicated to all branch managers their respective organizations' endorsement of the study and encouraged branch participation.

Subsequently, the first author visited each branch to personally distribute questionnaires to 358 FLEs who had been identified by the branch managers as eligible respondents. Participants completed the survey in small groups during their lunch breaks and returned it directly to the said author in a sealed envelope. In a cover letter attached to the survey, respondents were informed that their participation was voluntary, and they were also assured that their answers would remain confidential. Employees provided data on creativity-oriented HPWS, need satisfaction, creative process engagement, and demographics. Although the HR function of each of the two participating organizations is centralized, we were assured that implementation of HR practices varied across branches. The branch managers rated each employee's creative performance, with each manager rating an average of 8 employees (range, 3-16). The small branch size enabled branch managers to frequently interact with all FLEs, thereby getting to know their work very well; they were also responsible for conducting employee performance appraisals. We further asked branch managers to rate the extent to which creativity-oriented HPWS had been implemented at their branches. Finally, data on customer satisfaction were obtained from company records for the 6 months prior to and 6 months after the quarter of survey data collection.

Of the 358 questionnaires distributed, completed questionnaires were received from 329 FLEs and 51 branch managers. FLEs were predominantly female $(96 \%)$; their average age was 35.05 years $(S D=8.97)$; and their average position tenure was 5.82 years $(S D=6.07)$. Ninety-one percent of the branch managers were female; their average age was 34.40 years $(S D=5.93)$; and their average position tenure was 5.80 years $(S D=3.45)$.

\section{Measures}

Questionnaires were originally constructed in English but administered in Lithuanian following Brislin's (1986) recommended translation-back translation procedure. We then piloted the Lithuanian version of the questionnaire on a sample of 20 FLEs of a local retail bank. On the basis of the feedback obtained, we reworded a few items to ensure clarity. 
Perceived creativity-oriented HPWS. Given the absence of a generally accepted rationale for selecting HR practices to be included in measures of HPWS (Boselie, Dietz, \& Boon, 2005), we drew on Amabile's (1996) componential model of creativity to identify the practices included in our measure of HPWS. Specifically, we selected six HPWS domains and related items from the SHRM literature (Liao et al., 2009; Sun et al., 2007) to reflect the strategic focus of promoting creative performance. We ascertained the relevance of the items by interviewing $16 \mathrm{HR}$ managers, 4 sales directors, and a project manager drawn from diverse industries in Lithuania. In addition to ensuring the relevance of these domains (and the items), the interview data revealed another domain: playfulness at work. To assess content validity, six doctoral students in human resource management and organizational psychology at a university in central England sorted the items across the seven predicted domains (selection, performance appraisal, training, compensation, job design, employee participation and information sharing, and playfulness at work). Consistent with the recommended cutoff point of $60 \%$ to $70 \%$ for retaining items (Carlson, Kacmar, \& Williams, 2000), 31 of the 40 items were matched with the appropriate descriptions by at least four of the six judges.

To examine the validity of our measure, we contacted 362 FLEs to participate in an online survey to ascertain their experience of HPWS in their respective organizations. Of the FLEs contacted, 256 participated in the study and indicated the extent to which these HR practices were used in their respective organizations. We subsequently conducted an exploratory factor analysis with principal component analysis and oblique rotation to uncover the underlying factor structure of the HPWS measure (DeVellis, 2003). The exploratory factor analysis results revealed a seven-factor structure with eigenvalues greater than one, which explained $65.25 \%$ of the variance (Hair, Anderson, Tatham, \& Black, 1995). Only items with loadings $\geq .40$ on the intended factor were retained. Overall, 8 items were dropped because of poor loadings, cross loadings, and low commonalities, resulting in a total of 23 items representing seven dimensions of the creativity-oriented HPWS measure (scale items and exploratory factor analysis results reported in Table A1; see online supplement). Composite reliability for the creativity-oriented HPWS measure was .91, which implies high internal consistency of the newly developed measure, and the average variance extracted was .59 , which meets the suggested requirement for convergent validity of at least .50 (Fornell \& Larcker, 1981).

In addition to employees' questionnaires, we collected data from 31 supervisors at Time 2 on employee creative performance (seven items; Wang \& Netemeyer, 2004). We were able to match these ratings to those of 133 employees who had participated in the first wave. The correlation between creativity-oriented HPWS and supervisor-rated creative performance at Time $2(r=.22, p<.05)$ was significant, providing initial evidence for the predictive validity of the creativity-oriented HPWS measure.

We used the newly developed creativity-oriented HPWS scale to measure FLEs' perceived creativity-oriented HPWS. Respondents were requested to indicate the extent of their personal experiences and understanding of the HR practices that constituted the scale. Response options ranged from 1 (strongly disagree) to 6 (strongly agree). In this study, Cronbach's alpha for the creativity-oriented HPWS scale was .88 for the within level and .92 for the between level.

Need satisfaction. We assessed need satisfaction using the 21-item Basic Need Satisfaction at Work Scale reported by Deci et al. (2001). Sample items include "I do not feel very competent when I am at work" (need for competence, reverse coded), "I feel like I can make 
a lot of inputs to deciding how my job gets done" (need for autonomy), and "I consider the people I work with to be my friends" (need for relatedness). Response options ranged from 1 (not true at all) to 7 (very true). In this study, Cronbach's alpha for the need satisfaction scale was .80 for the within level and .82 for the between level.

Creative process engagement. We measured creative process engagement with an 11-item scale developed by Zhang and Bartol (2010). A representative item is "I think about the problem from multiple perspectives." Respondents indicated the frequency with which they engaged in each activity, with response options ranging from 1 (never) to 5 (very frequently). In this study, Cronbach's alpha for the creative process engagement scale was .83 for the within level and .86 for the between level.

Creative performance. Branch managers rated the creative performance of their subordinates participating in the survey using a seven-item scale developed by Wang and Netemeyer (2004) that had previously been used in a Lithuanian context (Martinaityte \& Sacramento, 2013). Response options ranged from 1 (strongly disagree) to 7 (strongly agree). In this study, a sample item is "This employee comes up with new ideas for satisfying customer needs." Cronbach's alpha for the creative performance scale was .93 for the within and .83 for the between level.

Branch-level average creative performance. Following prior research (Lüdtke et al., 2008) and as later explained in detail, we adopted a multilevel latent covariate approach to calculate branch creativity, thus operationalized as the latent group average of the individual ratings in each branch. We calculated within-group agreement, $r_{w g(j)}(\mathrm{James}$, Demaree, \& Wolf, 1984), and the intraclass correlation coefficients ICC1 and ICC2 (Bliese, 1998) to verify whether there was statistical support for examining creativity as a unit-level construct: mean $r_{w g(j)}=.91$ (range, .00-1), ICC1 $=.36$, and ICC2 $=.78, F(50,278)=4.588, p=.000$, providing statistical support for the examination of the construct at the unit level. We also considered employing a referent shift model (Chan, 1998) to capture a direct measure of branch (unit) creative performance. However, given that some managers had to rate up to 16 team members, we used average creative performance to accommodate the participating organizations' concern about the length of the supervisor survey.

Branch customer satisfaction. Data on customer satisfaction were obtained from company records. For both organizations, we were provided with a customer satisfaction index for each branch. In the cosmetics retailer, this assessment was conducted via mystery shoppers who visited each branch quarterly and rated each experience across customer satisfaction criteria previously agreed with the organization. A satisfaction index was calculated for each branch, with customer satisfaction varying between $75 \%$ and $97 \%$ for the period considered as our dependent variable. A sample item included "Would you recommend this shop to your friends?" In the retail bank, a random selection of clients was contacted each quarter and asked to provide ratings of customer satisfaction using a set survey. Each branch was attributed a target for customer satisfaction, and the data were calculated to reflect the percentage to which this target was achieved. In this case, customer satisfaction varied between 96\% and 106\%. A sample item included "Based on your experience, would you recommend this branch to 
your friends/relatives in the future?" We were provided with data for two quarters prior to and two quarters after the quarter in which we conducted our survey. Following Sung and Choi (2012), who measured team financial performance with data obtained 6 months after their survey data collection, our analysis included measurement of customer satisfaction at two time points (two quarters each): 6 months prior to and 6 months following data collection. As the two companies used different approaches to capture and record customer satisfaction, we standardized the values for each of the organizations separately before pooling the data (e.g., Lee, Stettler, \& Antonakis, 2011; Martinaityte \& Sacramento, 2013).

Controls. To rule out alternative explanations but at the same time limit the number of control variables and increase statistical power, we first examined which potential control variables significantly correlated with creative performance and customer satisfaction. At the individual, or within-group, level of analysis, we controlled for tenure, as this was the only demographic variable significantly related to creative performance. At the unit, or betweengroup, level of analysis, we added average employees' age in the branch and leader's tenure (Chang et al., 2014), as these were related to customer satisfaction. Additionally, we controlled for organization and branch size (obtained from company records), as smaller organizations are less likely to use HPWS (Aryee et al., 2012; Liao et al., 2009) but more likely to provide opportunities for closer interactions with customers, resulting in higher levels of customer satisfaction (Dietz, Pugh, \& Wiley 2004). We initially also controlled for individual branch managers' ratings of creativity-oriented HPWS per branch. However, as the results remained unaltered and to balance the number of controls and save degrees of freedom, we report instead the results without including leaders' ratings of HPWS. Finally, following Jiang, Chuang, and Chiao (2015) and because past performance may influence the relationship between our studied variables and future performance (Wright, Gardner, Moynihan, \& Allen, 2005), we controlled for branch customer satisfaction levels in the 6 months prior to the quarter of the survey data collection.

\section{Discriminant Validity of the Constructs}

Given the nested structure of the data, we started by conducting a multilevel confirmatory factor analysis (MCFA) using Mplus 7.4 (Muthén \& Muthén, 1998-2011) to examine construct distinctiveness. Given the relatively small sample size in relation to the number of items, we adopted item-parceling procedures to reach a more adequate ratio (Nasser \& Wisenbaker, 2003). Following Hox, Maas, and Brinkhuis's (2010) recommendation and to enhance the accuracy of statistical tests, we used weighted least squares mean-adjusted estimator because it is more appropriate when the number of between-level cases is low. We used the comparative fit index (CFI), standardized root mean square residual (SRMR), and root mean square error of approximation (RMSEA) to examine model fit. We compared the fit of our hypothesized four-factor model-including perceived creativity-oriented HPWS, need satisfaction, creative process engagement, and individual creative performance - with a series of three-factor models collapsing into one factor: creative process engagement and individual creative performance, perceived creativity-oriented HPWS and individual creative performance, perceived creativity-oriented HPWS and creative process engagement, and perceived creativity-oriented HPWS and need satisfaction. We also compared it with a two-factor model combining all self-reported variables and to a one-factor model combining 
all constructs. The MCFA results showed that the proposed four-factor structure had the best fit to the data $(\mathrm{CFI}=.92$, RMSEA $=.05$, SRMR-within $=.06$, SRMR-between $=.29)$. The SRMR fit index for the within part of the model (.06) is better than that for the between part of the model (.29), suggesting that the results for the between component should be interpreted with caution (CFA results reported in Table B1; see online supplement).

To obtain the fit indices for the within and between components separately, we ran the CFA model for both the within- and between-groups covariance matrices separately (Zyphur, Kaplan, \& Christian, 2008). In line with the above results and in relation to the within level, the four-factor model fit the data reasonably well $(\mathrm{CFI}=.91$, RMSEA $=.07)$, producing the best fit when compared with the alternative models. However, the CFA conducted in the between-groups variance matrix produced a poor fit $(\mathrm{CFI}=.31$, $\mathrm{RMSEA}=.51)$, but this was still the best model. Thus, although the evidence supporting the distinctiveness of the constructs is not as strong as desirable at the between level, it clearly supports the existence of four distinct constructs at the within level. As our theory is focused on the within level, we proceeded with the testing of the model. We, however, note that the between-level results must be interpreted with caution.

\section{Analytical Approach}

We tested our hypotheses using multilevel structural equation modeling employing the procedures recommended by Preacher and colleagues (Preacher, Zhang, \& Zyphur, 2011; Preacher et al., 2010). Given that most of our variables were captured at the individual (within-group) level (L1) and our participants were nested in branches (L2), our measures comprised both within and between variance, thus justifying the appropriateness of using a multilevel analytical approach. Failing to account for this dual source of variance would have led to the calculation of biased estimates for both direct and indirect effects (Preacher et al., 2010; Preacher et al., 2011). Furthermore, by adopting Preacher and colleagues' procedures (2010), which we describe next, we avoided the problems of conflated estimates of betweenand within-level components of indirect effects. We note that we first attempted to estimate the structural and measurement model simultaneously. However, given the complex nature of our path model, we encountered the same difficulties as previously documented (Muthén \& Muthén, 1998-2011), so we instead used scale means.

Although the focus of analysis for Hypotheses 1 to 8 is the individual processes, as our theorizing so reflects, it is also relevant from an exploratory perspective, to examine whether these processes follow an isomorphic model (Chan, 1998). We note that although a full mediation linking perceived creativity-oriented HPWS to customer satisfaction could be inferred from our rationale, we do not specify such a hypothesis. As explained by different authors (Preacher et al., 2010), the between-variance component of a variable can only influence the between-variance component of another variable, with the same being true in relation to the within-variance components. Consequently, it would be incorrect to hypothesize a relationship that implicitly carries an association involving both within- and between-variance components (K. Preacher, personal communication, October 12, 2015). This total mediation effect relating perceived creativity-oriented HPWS to customer satisfaction can thus be analyzed only in relation to the between-variance components of perceived creativity-oriented HPWS, need satisfaction, creative process engagement, and creative performance, which we also tested on an exploratory basis. 
All our hypotheses were tested using Mplus 7.4 (Muthén \& Muthén, 1998-2011) with robust maximum likelihood estimation using a type TWOLEVEL. Following Ludtke and colleagues (2008), we employed a random coefficients model allowing the intercept to vary across units. Lüdtke and colleagues found that the use of group mean manifest variables can lead to substantially biased contextual effects, and they suggested instead the use of a multilevel latent covariate approach. Accordingly, we used the latent unobserved group mean for each variable by entering the same variable in both the within- and between-model statements and by allowing Mplus to create the latent group variable used in the calculation of the between effects. We computed $r_{w g(j)}$ and ICC measures for each remaining variable. As was the case for creative performance reported above, $r_{w g(j)}$ values were all $>.70$ (HPWS $=.96$, need satisfaction $=.94$, and creative process engagement $=.95)$, indicating a strong agreement within the branches (LeBreton \& Senter, 2008). However, in contrast to creative performance, the ICCs for the other measures were rather low (respectively: ICC1 and ICC2 = .17 and .55 for creativity-oriented HPWS, .09 and .36 for need satisfaction, and .13 and .46 for creative process engagement), suggesting caution in interpreting the unit-level results involving these variables. These results might also justify the lower fit indices reported earlier in relation to the between-level MCFA.

Thus, we tested our hypotheses by defining our model at both the within and between levels of analysis (Preacher et al., 2010). At the within level, all possible direct paths among perceived creativity-oriented HPWS, need satisfaction, creative process engagement, and creative performance were established. In addition, at the between level, we regressed customer satisfaction on average branch creative performance. Using the Model Constraints command in Mplus and applying the product-of-coefficients approach (Fox, 1980; Preacher et al., 2011), we then tested the three alternative mediation models at both the within and between levels by multiplying the coefficients involved in each mediation chain. This procedure enabled us to obtain the coefficient, standard error, and confidence interval for each indirect effect. The fit indices for the estimated overall model are acceptable, CFI $=.94$, RMSEA $=.04$. While the fit index for the within portion of the model is suggestive of a good fit, SRMR-within $=.008$, the between part of the model shows a poor fit to the data, SRMRbetween $=.124$, which suggests that although our proposed model finds support at the individual level, the relationships are likely to unfold differently at the unit level.

\section{Results}

\section{Tests of Hypotheses}

Given the multilevel structure of the data, we present the disaggregated correlations in Table 1, which includes both the within- and between-level correlations between all variables included in the testing of the model (e.g., Zyphur et al., 2008).

The results of all direct and indirect relationships proposed in our model are shown in Table 2. Hypothesis 1, suggesting that perceived creativity-oriented HPWS would be related to need satisfaction, was supported $(b=0.50, p<.001)$. However, Hypothesis 2 , suggesting a main effect of perceived creativity-oriented HPWS on creative process engagement $(b=$ $0.12, n s$ ), was not supported. Hypothesis 3 , proposing that need satisfaction would be positively related to creative process engagement, received only partial support, as the effect was marginally significant $(b=0.12, p=.075)$. Hypothesis 4 , proposing a main effect of need 
Table 1

Disaggregated Correlations Among Study Variables

\begin{tabular}{lcccccccccrr}
\hline Variable & $M$ & 1 & 2 & 3 & 4 & 5 & 6 & 7 & 8 & 9 & 10 \\
\hline 1. CS+6 & 0.06 & & & & & & & & & \\
2. CR & 5.07 & $.34^{* *}$ & & .09 & $.13^{* *}$ & $.15^{* *}$ & -.05 & & & \\
3. CPE & 3.64 & -.21 & .02 & & $.22^{* *}$ & .01 & $.22^{* *}$ & & & & \\
4. NS & 5.20 & -.13 & $.53^{* *}$ & $.48^{* *}$ & & .03 & $.43^{* *}$ & & & & \\
5. TN & 5.67 & .06 & -.06 & $.52^{* *}$ & .11 & & .08 & & & & \\
6. HPWS & 4.16 & .11 & $.64^{* *}$ & $.57^{* *}$ & $.66^{* *}$ & $.32^{* *}$ & & & & & \\
7. ORG & 0.58 & -.15 & .05 & $.58^{* *}$ & .05 & $.64^{* *}$ & $.62^{* *}$ & & & & \\
8. AGE & 34.6 & $-.29^{*}$ & .06 & $.63^{* *}$ & $.28^{*}$ & $.81^{* *}$ & $.26^{*}$ & $.54^{* *}$ & & & \\
9. LTN & 5.95 & $-.23^{\dagger}$ & -.13 & .19 & .49 & .23 & .04 & -.03 & $.28^{*}$ & & \\
10. SIZE & 7.70 & -.15 & -.17 & .01 & -.20 & .08 & .04 & $.45^{* *}$ & .14 & -.02 & \\
11. CS-6 & 0.03 & $.49^{* *}$ & .11 & .05 & -.16 & $-.24^{*}$ & .04 & -.03 & $-.27^{*}$ & .04 & -.12 \\
\hline
\end{tabular}

Note: Lower/upper diagonal indicates between/within-group correlations. CS+6 = customer satisfaction 6 months after the survey data collection; $\mathrm{CR}=$ creative performance; $\mathrm{CPE}=$ creative process engagement; NS = need satisfaction; TN = employee tenure; HPWS = high-performance work system; ORG = organization; $\mathrm{AGE}=$ average employee age; LTN = leader's tenure; SIZE = branch size; CS- 6 = customer satisfaction 6 months before the survey data collection.

$\dagger p=.05$.

$* p<.05$.

$* * p<.01$.

satisfaction on creative performance, was supported $(b=0.26, p<.01)$. Hypothesis 5 , suggesting that creative process engagement would relate to creative performance, was not supported $(b=0.15, n s)$. In relation to the proposed indirect effects, the serial mediation linking perceived creativity-oriented HPWS to creative performance via need satisfaction and creative process engagement (H6) was not supported - the estimated size of the indirect effect was $0.01(0.01), 95 \%$ CI $[-0.01,0.03]$. The parallel mediation effect via creative process engagement (H8) was not supported as well-the effect was $0.02(0.02), 95 \%$ CI [ -0.02 , $0.05]$. However, we did find support for the proposed parallel mediation via need satisfaction (H7); the effect was $0.13(0.05), 95 \%$ CI [0.03, 0.23]. To further probe the distribution of the indirect effect, we applied a Monte Carlo approach (Preacher \& Selig, 2012) using Selig and Preacher's (2008) web-based tool (available on http://quantpsy.org/) to find a result similar to that reported above: $95 \%$ CI $[0.05,0.23]$. This model accounted for $9.79 \%$ of the variance in within-level creative performance. These results lend support to our hypothesized indirect effect of perceived creativity-oriented HPWS on creative performance via need satisfaction.

As described above, we also examined, in an exploratory manner, the same relationships at the unit level of analysis. Interestingly, an inspection of the same coefficients at the between level revealed a different pattern of relationships. Average perceived creativity-oriented HPWS did have a positive effect on average creative process engagement $(b=0.52, p<.05)$ but not on average need satisfaction $(b=0.34, p>.05)$. Average perceived creativity-oriented HPWS was also positively related to average branch creative performance $(b=3.58, p<.01)$, even after accounting for the effects of average need satisfaction and average creative process engagement. Neither average creative process engagement $(b=-3.31, p>.05)$ nor average need satisfaction $(b=2.04, p>.05)$ was related to branch-level average employee 
Table 2

Estimations of Direct and Indirect Effects

\begin{tabular}{|c|c|c|c|}
\hline & Coefficient & $S E$ & $95 \% \mathrm{CI}$ \\
\hline \multicolumn{4}{|l|}{ Individual-level direct effects } \\
\hline 1. Creativity-oriented HPWS $\rightarrow$ Need satisfaction (H1) & $0.50^{* * *}$ & 0.06 & {$[0.39,0.62]$} \\
\hline 2. Creativity-oriented HPWS $\rightarrow$ Creative process engagement $(\mathrm{H} 2)$ & 0.12 & 0.08 & {$[-0.03,0.27]$} \\
\hline 3. Need satisfaction $\rightarrow$ Creative process engagement $(\mathrm{H} 3)$ & $0.12^{\dagger}$ & 0.07 & {$[0.01,0.23]^{\mathrm{a}}$} \\
\hline 4. Need satisfaction $\rightarrow$ Creative performance $(\mathrm{H} 4)$ & $0.26^{* *}$ & 0.10 & {$[0.07,0.46]$} \\
\hline 5. Creative process engagement $\rightarrow$ Creative performance (H5) & 0.15 & 0.12 & {$[-0.09,0.30]$} \\
\hline 6. Creativity-oriented HPWS $\rightarrow$ Creative performance & $-0.20^{*}$ & 0.09 & {$[-0.38,-0.02]$} \\
\hline \multicolumn{4}{|l|}{ Individual-level indirect effects } \\
\hline $\begin{array}{l}\text { 7. Creativity-oriented HPWS } \rightarrow \text { Need satisfaction } \rightarrow \text { Creative } \\
\text { process engagement } \rightarrow \text { Creative performance }(\mathrm{H} 6)\end{array}$ & 0.01 & 0.01 & {$[-0.01,0.03]$} \\
\hline $\begin{array}{l}\text { 8. Creativity-oriented HPWS } \rightarrow \text { Need satisfaction } \rightarrow \text { Creative } \\
\text { performance }(\mathrm{H} 7)\end{array}$ & $0.13^{* *}$ & 0.05 & {$[0.03,0.23]$} \\
\hline $\begin{array}{l}\text { 9. Creativity-oriented HPWS } \rightarrow \text { Creative process engagement } \rightarrow \\
\text { Creative performance (H8) }\end{array}$ & 0.02 & 0.02 & {$[-0.02,0.05]$} \\
\hline \multicolumn{4}{|l|}{ Group-level direct effects } \\
\hline 10. Average creativity-oriented HPWS $\rightarrow$ average need satisfaction & 0.34 & 0.25 & {$[-0.15,0.84]$} \\
\hline $\begin{array}{l}\text { 11. Average creativity-oriented HPWS } \rightarrow \text { average creative process } \\
\text { engagement }\end{array}$ & $0.52^{*}$ & 0.22 & {$[0.08,0.96]$} \\
\hline 12. Average need satisfaction $\rightarrow$ average creative process engagement & 0.32 & 0.32 & {$[-0.31,0.95]$} \\
\hline 13. Average need satisfaction $\rightarrow$ average creative performance & 2.04 & 1.72 & {$[-1.34,5.42]$} \\
\hline $\begin{array}{l}\text { 14. Average creative process engagement } \rightarrow \text { average creative } \\
\text { performance }\end{array}$ & -3.31 & 2.08 & {$[-7.39,0.77]$} \\
\hline $\begin{array}{l}\text { 15. Average creativity-oriented HPWS } \rightarrow \text { average creative } \\
\text { performance }\end{array}$ & $3.58^{* *}$ & 1.30 & {$[1.03,6.14]$} \\
\hline 16. Average creative performance $\rightarrow$ customer satisfaction (H9) & $0.85^{* *}$ & 0.29 & {$[0.28,1.42]$} \\
\hline \multicolumn{4}{|l|}{ Group-level indirect effects } \\
\hline $\begin{array}{l}\text { 17. Average creativity-oriented HPWS } \rightarrow \text { average creative } \\
\text { performance } \rightarrow \text { customer satisfaction }\end{array}$ & $3.04^{\dagger}$ & 1.63 & {$[0.35,5.72]^{\mathrm{a}}$} \\
\hline
\end{tabular}

Note: Unit level, $n=50$; individual level, $n=264$. CI = confidence interval; HPWS = high-performance work system. aWe report $90 \% \mathrm{CI}$, which is justifiable given a one-sided hypothesis.

$\dagger p<.10$.

$* p<.05$.

$* * p<.01$.

$* * * p<.001$.

creative performance. Consistent with these results, none of the proposed mediation effects was supported at the between level of analysis. This model accounted for $91 \%$ of the variance in between-level creative performance.

The crucial hypothesis at the between level, however, was the relationship between average branch creative performance and branch customer satisfaction (H9), which was supported $(b=0.85, p<.01)$. Given that the mediating mechanisms shown to operate as hypothesized at the individual or within level were not replicated at the unit level of analysis, we additionally tested whether the effect of average perceived creativity-oriented HPWS on customer branch satisfaction was mediated by only average branch creative performance. We found marginal support for this mediation, with an effect of $3.04(1.63), 90 \% \mathrm{CI}[0.35,5.72]$. 
This finding suggests that at the branch level, the effects of perceived creativity-oriented HPWS occur via different mechanisms from that which we proposed and which was supported at the individual or within level. To further probe the distribution of the indirect effect, we applied a Monte Carlo approach (Preacher \& Selig, 2012) as above, 95\% CI [0.47, 6.96]. The between-level model accounted for $93.62 \%$ of the variance in customer satisfaction.

There are a few other results worthy of comment. The negative coefficient for the within relationship between perceived creativity-oriented HPWS and creative performance (coefficient $=-.20, p<.05)$ as well as the nonsignificant relationship between within perceived creativity-oriented HPWS and creative process engagement (coefficient $=.12$ ) might seem at variance with our theorizing. However, in the presence of other variables, these coefficients should not be interpreted as the isolated effect of $X$ on $Y$ but as the effect of $X$ on $Y$ when all other variables are held constant. When examined in isolation, the relationship between perceived creativity-oriented HPWS and creative performance is nonsignificant (coefficient = -.04 ), and the relationship between perceived creativity-oriented HPWS and creative process engagement is positive and significant (coefficient $=.21, p<.05$ ).

\section{Discussion}

The results of our multilevel structural equation modeling analyses revealed four salient findings. First, perceived creativity-oriented HPWS related to need satisfaction but not to creative process engagement. Second, need satisfaction but not creative process engagement related to creative performance. Third, the proposed indirect influence of perceived creativity-oriented HPWS on creative performance was through need satisfaction but not creative process engagement. Fourth, average branch creative performance related to branch customer satisfaction. We discuss the implications of these findings in the succeeding sections.

\section{Theoretical Implications}

First, our finding that need satisfaction mediates the influence of perceived creativityoriented HPWS on creative performance underscores the relevance of SDT as a framework for explicating the documented performance implications of HPWS, particularly on creative performance (Chang et al., 2014). As an adaptive work-related behavior, FLEs require not only discretion but also competence and trust (which stems from a sense of belonging) to customize the service delivery to meet the idiosyncratic needs of customers. Perceived creativity-oriented HPWS provides the nutriments to satisfy these needs, which in turn leads to creative performance. Although prior research (Gardner et al., 2011) invoked SDT to account for the influence of the three HPWS components on aggregate turnover, it did not examine the role of need satisfaction in these relationships. Additionally, although Marescaux and colleagues (2013) reported partial support for SDT, they examined the mediating influence of needs (autonomy, competence, relatedness) on the relationship between single HR practices and employee attitudes (organizational commitment and turnover intentions). Our focus on a global measure of need satisfaction as well as a system of HR practices as antecedents to creative performance complements their findings regarding the utility of SDT as an alternative framework for examining the performance implications of perceived HPWS.

Second, our finding that neither the hypothesized serial mediation nor the alternative pathway (through creative process engagement) received support rules out the alternative 
explanations and provides further evidence of the utility of SDT in the context of our study. Although creative process engagement has been shown to relate to creative performance (Huang et al., 2016; Zhang \& Bartol, 2010), it was unrelated to creative performance in this study. The inability of creative process engagement to mediate the relationship between perceived creativity-oriented HPWS and creative performance may stem from the service context of our study relative to the IT/technology contexts where creative process engagement has been shown to relate to creative performance (Huang et al., 2016; Zhang \& Bartol, 2010). In such contexts, creative process engagement may not be as time bound as in a service context, where the production and consumption of the service delivery occur simultaneously. In service contexts, FLEs may have to balance a need to customize the service delivery with its speed, which may therefore weaken the creative process engagementcreative performance relationship. Future research is needed to further probe our findings and subject the intuitive plausibility of our explanation to empirical confirmation.

Third, our finding that average creative performance relates to branch customer satisfaction is consistent with Dong and colleagues' (2015) finding at the individual level. Additionally, our finding is consistent with Coelho and colleagues' (2011) proposition regarding the link between the creative performance of FLEs and customer-related outcomes, such as customer satisfaction. As customer needs and expectations become increasingly diverse and FLEs have to customize the service delivery to meet or even exceed such needs and expectations, it is important that research examine the impact of adaptive behaviors on customer-related outcomes such as customer satisfaction at both individual and unit levels. The average creative performance-branch customer satisfaction relationship that we uncovered extends Wilder and colleagues' (2014) work by documenting creative performance, a component of adaptive service offering, as an antecedent to customer satisfaction. This finding receives further credence in light of the fact that not only did we control for the previous 6 months of branch customer satisfaction, but our customer satisfaction data were obtained in the two quarters ( 6 months) after the quarter of our survey data. The diverse needs and expectations of customers and the uncertainty that this injects into the service delivery process suggest that enhancing customers' experience of the service delivery or delighting customers will increasingly stem from FLEs' creative rather than prescribed role performance.

Fourth and although not formally hypothesized, our findings revealed that average perceived creativity-oriented HPWS related to average creative performance, which in turn influenced customer satisfaction. This finding reinforces the notion that HPWS influences operational outcomes via employee attitudes and behaviors (Jiang et al., 2012). Additionally, it provides a preliminary explanation for Liao and colleagues' (2009) finding that average perceived HPWS did not directly influence customer satisfaction. Our study therefore provides an initial opportunity to examine, across levels, the influence of perceived creativityoriented HPWS on customer satisfaction through creative performance. However, given that this relationship at the unit level did not occur through the motivating mechanism of need satisfaction as at the individual level, future research should not only replicate our findings but also explore the mechanisms that underpin this relationship at the unit level. As prior research that examined the performance implications of HPWS focused primarily on unitlevel management-rated HPWS (Sun et al., 2007), our focus on average perceived creativityoriented HPWS underscores the importance of understanding employees' experience or perceptions of HPWS (Kehoe \& Wright, 2013; Liao et al., 2009). We must, however, note 
that the ICC values for creative process engagement, need satisfaction, and creativity-oriented perceived HPWS were below the standards commonly applied, suggesting caution in the interpretation of the results of the unit, or between-level, relationships that we examined.

Last, the call for research to tailor HPWS to the strategic goals of an organization suggests a need to move away from generic HPWS if organizations are to build the internal capability to effectively implement these goals. We therefore extend the SHRM literature by using a strategically focused HPWS that motivates FLEs to customize or adapt the service delivery to the needs of customers. Drawing on Amabile's (1996) componential model as well as generic HR practices (e.g., Sun et al., 2007), we used such an HPWS. Although this measure shares some of the elements of a generic HPWS, we uncovered a unique element: playfulness at work. Examples of practices that define this element include initiatives to promote play and fun at work, as well as time and space to enjoy nonwork-related activities. These items suggest that the playfulness-at-work HPWS domain that we uncovered reflects what Mainemelis and Ronson (2006) termed diversionary play in their theory of play and creativity in organizational settings. As part of the larger work context, they suggested that diversionary play fosters social bonds among employees and therefore enhances the range and depth of useful inputs obtained from colleagues (Mainemelis \& Ronson, 2006). This underscores the documented role of social interactions (Perry-Smith, 2006) as well as a humorous work climate (Slatten, Svensson, \& Svaeri, 2011) in engendering creative performance, especially in the interdependent and uncertain contexts in which FLEs increasingly deliver the service experience.

\section{Practical Implications}

Our finding that FLEs' creative performance relates to customer satisfaction, coupled with the financial implications of customer satisfaction as documented by the American Customer Satisfaction Index (Fornell, Johnson, Anderson, Cha, \& Bryant, 1996), suggests that service organizations must seek to understand the drivers of this form of performance. While we acknowledge the potential dilemma that this poses for service organizations in terms of making a choice between standardization versus customization of the service delivery (Gilson et al., 2005; Hong et al., 2014), the satisfaction of the increasingly unique and diverse needs of customers suggests a move away from scripted behaviors to creating facilitative contexts that promote autonomous regulation in the service delivery process.

Our findings suggest that such facilitative contexts may be fostered through the adoption of an internally coherent set of HR practices that are geared to developing the contexts and skills necessary to motivate creative performance. Although generic HPWS has been shown to relate to creative performance (Chang et al., 2014), the creativity-oriented HPWS that we reported in this study may be better suited to developing the skills and motivation necessary to achieve sustained competitive advantage through FLEs' creative performance. This is particularly important given Becker and Huselid's (2006) call for SHRM research to focus on helping organizations to develop the strategic capabilities to facilitate effective strategy implementation. The increasing need for service organizations to compete through service customization makes the creativity-oriented HPWS scale reported in this study a tool for building these strategic capabilities (Hong et al., 2014). Consequently, supervisors who are 
responsible for implementing these practices must be trained to ensure that their behaviors reinforce the intended messages (Pak \& Kim, in press).

\section{Limitations and Directions for Future Research}

This study has some limitations that suggest opportunities for future research. First, although we controlled for data on customer satisfaction 6 months prior to our study and even though the customer satisfaction data were collected over the 6 months after the data on our study variables were collected, data on our independent and mediating variables were obtained at the same point in time. Future research that employs a longitudinal or multiwave research design will be better placed to ascertain the causal status of the relationships that we reported. Additionally, although data on our study variables were obtained from three sources, data on the individual-level constructs of perceived creativity-oriented HPWS, need satisfaction, and creative process engagement were obtained from the same respondents, which suggests a possibility of method bias influencing the relationships that we reported. However, support for the mediating influence of need satisfaction but not creative process engagement suggests that our results are not entirely attributable to method bias. Nevertheless, future research may collect data from peers, particularly on creative process engagement, to rule out this issue.

Second, although we developed a strategically focused HPWS that was grounded in Amabile's (1983) componential model (creativity-oriented skills, domain-specific skills, and task motivation), we did not specifically measure the extent to which this HPWS measure fosters the development of domain-relevant (Liu et al., in press) and creativity-relevant skills through which perceived HPWS may influence FLEs' behavioral reactions (Jiang et al., 2015). Additionally, although our findings suggest support for SDT in accounting for our hypothesized relationships, future research should integrate SDT and ability, motivation, and opportunity frameworks to more completely understand the role of HPWS in developing the strategic capabilities necessary to ensure strategy implementation. Related to this task and given the documented importance of employees' experience and, therefore, perceptions of HPWS, future research should examine the role of supervisors in the implementation of HPWS (Pak \& Kim, in press).

Last, while research has shown discretionary behaviors, such as proactive customer service performance (Raub \& Liao, 2012) and creative performance (as in this study), to relate to customer satisfaction, we do not yet understand the boundary conditions of this relationship. Given the expense involved in building the strategic capability to customize or adapt the service delivery to suit the needs of customers, it will be helpful for research to uncover when standardization or customization of the service delivery (Gilson et al., 2005) will lead to customer satisfaction and, ultimately, to the financial viability of service organizations.

\section{Conclusion}

Drawing on SDT, we proposed and tested a multilevel model of how a creativity-oriented HPWS works to influence customer satisfaction. Our findings revealed that perceived creativity-oriented HPWS provides the nutriments to satisfy the psychological needs of FLEs, which in turn influences creative performance. Furthermore, average creative performance influences branch customer satisfaction. We hope that these findings, as well as the directions for research that we mapped out, will spur the investment of research effort into more fully 
understanding how service organizations can develop the capability to execute their strategy of achieving sustained competitive advantage through service excellence.

\section{References}

Agnihotri, R., Rapp, A. A, Andzulis, J., \& Gabler, C. B. 2014. Examining the drivers and performance implications of boundary spanner creativity. Journal of Service Research, 17: 164-181.

Ahearne, M., Mathieu, J., \& Rapp, A. 2005. To empower or not to empower your sales force? An empirical examination of the influence of leadership empowerment behavior on customer satisfaction and performance. Journal of Applied Psychology, 90: 945-955.

Amabile, T. M. 1983. The social-psychology of creativity: A componential conceptualization. Journal of Personality and Social Psychology, 45: 357-376.

Amabile, T. M. 1996. Creativity in context. Boulder, CO: Westview.

Applebaum, E., Bailey, T., Berg, P., \& Kalleberg, A. 2000. Manufacturing advantage: Why high-performance work systems pay off. Ithaca, NY: ILR Press.

Arnold, M. J., Reynolds, K. E., Ponder, N., \& Lueg, J. E. 2005. Customer delight in a retail context: Investigating delightful and terrible shopping experiences. Journal of Business Research, 58: 1132-1145.

Aryee, S., Walumbwa, F. O., Mondejar, R., \& Chu, C. W. L. 2015. Accounting for the influence of overall justice on job performance: Integrating self-determination and social exchange theories. Journal of Management Studies, 52: 231-252.

Aryee, S., Walumbwa, F. O., Seidu, E. Y. M., \& Otaye, L. E. 2012. Impact of high-performance work systems on individual- and branch-level performance: Test of a multilevel model of intermediate linkages. Journal of Applied Psychology, 97: 287-300.

Barnes, D. C., Beauchamp, M. B., \& Webster, C. 2010. To delight, or not to delight? This is the question service firms must address. Journal of Marketing Theory and Practice, 18: 275-284.

Becker, B. E., \& Huselid, M. A. 2006. Strategic human resources management: Where do we go from here? Journal of Management, 32: 898-925.

Bliese, P. D. 1998. Group size, ICC values, and group-level correlations: A simulation. Organizational Research Methods, 1: 355-373.

Boselie, P., Dietz, G., \& Boon, C. 2005. Commonalities and contradictions in HRM and performance research. Human Resource Management Journal, 15: 67-94.

Bowen, D. E., \& Ostroff, C. 2004. Understanding HRM-firm performance linkages: The role of the "strength" of the HRM system. Academy of Management Review, 29: 204-221.

Bowen, J., \& Ford, R. C. 2002. Managing service organizations: Does having a "thing" make a difference? Journal of Management, 28: 447-469.

Brislin, R. W. 1986. The wording and translation of research instruments. In W. J. Lonner \& J. W. Berry (Eds.), Field methods in cross-cultural research (pp. 137-164). Beverly Hills, CA: Sage.

Carlson, D. S., Kacmar, M. K., \& Williams, L. J. 2000. Construction and initial validation of a multidimensional measure of work-family conflict. Journal of Vocational Behavior, 56: 249-276.

Chan, D. 1998. Functional relations among constructs in the same content domain at different levels of analysis: A typology of composition models. Journal of Applied Psychology, 83: 234-246.

Chang, S., Jia, L., Takeuchi, R., \& Cai, Y. 2014. Do high-commitment work systems affect creativity? A multilevel combinational approach to employee creativity. Journal of Applied Psychology, 99: 665-680.

Chuang, C., Jackson, S. E., \& Jiang, Y. 2016. Can knowledge-intensive teamwork be managed? Examining the roles of HRM systems, leadership, and tacit knowledge. Journal of Management, 42: 524-554.

Chuang, C., \& Liao, H. 2010. Strategic human resource management in service context: Taking care of business by taking care of employees and customers. Personnel Psychology, 63: 153-196.

Coelho, F., Augusto, M., \& Lages, F. L. 2011. Contextual factors and the creativity of frontline employees: The mediating effects of role stress and intrinsic motivation. Journal of Retailing, 87: 31-45.

Deci, E. L., \& Ryan, R. M. 2000. The "what" and "why" of goal pursuits: Human needs and the self-determination of behavior. Psychological Inquiry, 11: 227-268.

Deci, E. L., Ryan, R. M., Gagné, M., Leone, D. R., Usunov, J., \& Kornazheva, B. P. 2001. Need satisfaction, motivation, and well-being in the work organizations of a former Eastern Bloc country. Personality and Social Psychology Bulletin, 27: 930-942. 
DeVellis, R. F. 2003. Scale development: Theory and applications (2nd ed.). Newbury Park, CA: Sage.

Dietz, J., Pugh, S. D., \& Wiley, J. W. 2004. Service climate effects on customer attitudes: An examination of boundary conditions. Academy of Management Journal, 47: 81-92.

Dong, Y. T., Liao, H., Chuang, A., Zhou, J., \& Campbell, E. M. 2015. Fostering employee service creativity: Joint effects of customer empowering behaviors and supervisory empowering leadership. Journal of Applied Psychology, 100: 1364-1380.

Fornell, C., Johnson, M. D., Anderson, E. W., Cha, J., \& Bryant, B. E. 1996. The American customer satisfaction index: Nature, purpose, and findings. Journal of Marketing, 60: 7-18.

Fornell, C., \& Larcker, D. F. 1981. Structural equation models with unobservable variables and measurement error: Algebra and statistics. Journal of Marketing Research, 18: 382-388.

Fox, J. 1980. Effect analysis in structural equation models. Sociological Methods and Research, 9: 3-28.

Gagné, M., \& Deci, E. L. 2005. Self-determination theory and work motivation. Journal of Organizational Behavior, 26: $331-362$.

Gardner, T. M., Wright, P. M., \& Moynihan, L. M. 2011. The impact of motivation, empowerment, and skillenhancing practices on aggregate voluntary turnover: The mediating effect of collective affective commitment. Personnel Psychology, 64: 315-350.

Gilson, L. L., Mathieu, J. E., Shalley, C. E., \& Ruddy, T. M. 2005. Creativity and standardization: Complimentary or conflicting drivers of team effectiveness. Academy of Management Journal, 48: 521-531.

Gilson, L. L., \& Shalley, C. E. 2004. A little creativity goes a long way: An examination of team's engagement in the creative process. Journal of Management, 30: 453-470.

Greguras, G. J., \& Diefendorff, J. M. 2009. Different fits satisfy different needs: Linking person-environment fit to employee commitment and performance using self-determination theory. Journal of Applied Psychology, 94: 465-477.

Gwinner, K. P., Bitner, M. J., Brown, S. W., \& Kumar, A. 2005. Service customization through employee adaptiveness. Journal of Service Research, 8: 131-148.

Hair, J. F., Anderson, R. E., Tatham, R. L., \& Black, W. C. 1995. Multivariate data analysis (4th ed.). Englewood Cliff, NJ: Prentice Hall.

Hong, Y., Liao, H., Hu, J., \& Jiang, K. 2013. Missing link in the service chain: A meta-analytic review of the antecedents, consequences, and moderators of service climate. Journal of Applied Psychology, 98: 237-267.

Hong, Y., Liao, H., Raub, S., \& Han, J. H. 2016. What it takes to get proactive: An integrative multilevel model of the antecedents of personal initiative. Journal of Applied Psychology, 101: 687-701

Hong, Y., Liao, H., Sturman, M. C., \& Zhou, Y. 2014. Competing through customization: Using human resource management to create strategic capabilities. Organizational Psychology Review, 4: 124-147.

Hox, J. J., Maas, C. J. M., \& Brinkhuis, M. J. S. 2010. The effect of estimation method and sample size in multilevel structural equation modeling. Statistica Neerlandica, 64: 157-170.

Huang, L., Krasikova, D. V., \& Liu, D. 2016. I can do it, so can you: The role of leader creative self-efficacy in facilitating follower creativity. Organizational Behavior and Human Decision Processes, 132: 49-62.

James, L. R., Demaree, R. G., \& Wolf, G. 1984. Estimating within-group interrater reliability with and without response bias. Journal of Applied Psychology, 69: 85-98.

Jiang, K., Chuang, C.-H., \& Chiao, Y.-C. 2015. Developing collective customer knowledge and service climate: The interaction between service-oriented high-performance work systems and service leadership. Journal of Applied Psychology, 100: 1089-1106.

Jiang, K., Lepak, D. P., Hu, J., \& Baer, J. C. 2012. How does human resource management influence organizational outcomes? A meta-analytic investigation of mediating mechanisms. Academy of Management Journal, 55: 1264-1294.

Kehoe, R. R., \& Wright, P. M. 2013. The impact of high-performance human resource practices on employees' attitudes and behaviors. Journal of Management, 39: 366-391.

LeBreton, J. M., \& Senter, J. L. 2008. Answers to 20 questions about interrater reliability and interrater agreement. Organizational Research Methods, 11: 815-852.

Lee, Y. T., Stettler, A., \& Antonakis, J. 2011. Incremental validity and indirect effect of ethical development on work performance. Personality and Individual Differences, 50: 1110-1115.

Lian, H., Ferris, D. L., \& Brown, D. J. 2012. Does power distance exacerbate or mitigate the effects of abusive supervision? It depends on the outcome. Journal of Applied Psychology, 97: 107-123. 
Liao, H., Toya, K., Lepak, D. P., \& Hong, Y. 2009. Do they see eye to eye? Management and employee perspectives of high performance work systems and influence processes on service quality. Journal of Applied Psychology, 94: 371-391.

Liu, D., Gong, Y., Zhou, J., \& Huang, J. C. In press. Human resource systems, employee creativity, and firm innovation: The moderating role of firm ownership. Academy of Management Journal, doi:10.5465/amj.2015.0230.

Lüdtke, O., Marsh, H. W., Robitzsch, A., Trautwein, U., Asparouhov, T., \& Muthén, B. 2008. The multilevel latent covariate model: A new, more reliable approach to group-level effects in contextual studies. Psychological Methods, 13: 203-229.

Madjar, N., \& Ortiz-Walters, R. 2008. Customers as contributors and reliable evaluators of creativity in the service industry. Journal of Organizational Behavior, 29: 949-966.

Mainemelis, C., \& Ronson, S. 2006. Ideas are born in the fields of play: Towards a theory of play and creativity in organizational settings. Research in Organizational Behavior, 27: 81-131.

Marescaux, E., Winne, S. D., \& Sels, L. 2013. HR practices and HRM outcomes: The role of basic need satisfaction. Personnel Review, 42: 4-27.

Martinaityte, I., \& Sacramento, C. A. 2013. When creativity enhances sales effectiveness: The moderating role of leader-member exchange. Journal of Organizational Behavior, 34: 974-994.

Maslow, A. 1954. Motivation and personality. New York, NY: Harper.

Muthén, L. K., \& Muthén, B. O. 1998-2011. Mplus user's guide (6th ed.). Los Angeles, CA: Muthén \& Muthén.

Nasser, F., \& Wisenbaker, J. A. 2003. A Monte Carlo study investigating the impact of item parceling on measures of fit in confirmatory factor analysis. Educational and Psychological Measurement, 63: 729-757.

Oliver, R. L. 1977. Satisfaction: A behavioral perspective on the consumer. New York, NY: McGraw-Hill.

Pak, J., \& Kim, S. In press. Team manager's implementation, high performance work systems intensity, and performance: A multilevel investigation. Journal of Management, doi:10.1177/0149206316646829.

Perry-Smith, J. E. 2006. Social yet creative: The role of social relationships in facilitating individual creativity. Academy of Management Journal, 49: 85-101.

Preacher, K. J., \& Selig, J. P. 2012. Advantages of Monte Carlo confidence intervals for indirect effects. Communication Methods and Measures, 6: 77-98.

Preacher, K. J., Zhang, Z., \& Zyphur, M. J. 2011. Alternative methods for assessing mediation in multilevel data: The advantages of multilevel SEM. Structural Equation Modeling, 18: 161-182.

Preacher, K. J., Zyphur, M. J., \& Zhang, Z. 2010. A general multilevel SEM framework for assessing multilevel mediation. Psychological Methods, 15: 209-233.

Raub, S., \& Liao, H. 2012. Doing the right thing without being told: Joint effects of initiative climate and general self-efficacy on employee proactive customer service performance. Journal of Applied Psychology, 97: 651667.

Ryan, R. M., \& Deci, E. L. 2000. Self-determination theory and the facilitation of intrinsic motivation, social development, and well-being. American Psychologist, 55: 68-78.

Schneider, B., \& White, S. S. 2004. Service quality: Research perspectives. Thousand Oaks, CA: Sage.

Selig, J. P., \& Preacher, K. J. 2008. Monte Carlo method for assessing mediation: An interactive tool for creating confidence intervals for indirect effects. Retrieved from http://quantpsy.org/

Shalley, C. E., \& Gilson, L. L. 2004. What leaders need to know: A review of social and contextual factors that can foster or hinder creativity? Leadership Quarterly, 15: 33-53.

Sheldon, K. M., Turban, D. B., Brown, K. G., Barrick, M. R., \& Judge, T. A. 2003. Applying self-determination theory to organizational research. Research in Personnel and Human Resources Management, 22: 357-393.

Slatten, T., Svensson, G., \& Svaeri, S. 2011. Empowering leadership and the influence of a humorous work climate on service employees' creativity and innovative behaviour in frontline service jobs. International Journal of Quality and Service Sciences, 3: 267-284.

Sun, L. Y., Aryee, S., \& Law, K. S. 2007. High-performance human resource practices, citizenship behavior, and organizational performance: A relational perspective. Academy of Management Journal, 50: 558-577.

Sung, S. Y., \& Choi, J. M. 2012. Effects of team knowledge management on the creativity and financial performance of organizational teams. Organizational Behavior and Human Decision Processes, 118: 4-13.

Takeuchi, R., Lepak, D. P., Wang, H., \& Takeuchi, K. 2007. An empirical examination of the mechanisms mediating between high-performance work systems and the performance of Japanese organizations. Journal of Applied Psychology, 92: 1069-1083. 
Towler, A., Lezotte, D. V., \& Burke, M. J. 2011. The service climate-firm performance chain: The role of customer retention. Human Resource Management, 50: 391-406.

Vallerand, R. J. 2000. Deci and Ryan's self-determination theory: A view from the hierarchical model of intrinsic and extrinsic motivation. Psychological Inquiry, 11: 312-318.

Van den Broeck, A., Vansteenkiste, M., de Witte, H., Soenens, B., \& Lens, W. 2010. Capturing autonomy, competence, and relatedness at work: Construction and initial validation of the work-related basic need satisfaction scale. Journal of Occupational and Organizational Psychology, 83: 981-1002.

Wang, G., \& Netemeyer, R. G. 2004. Salesperson creative performance: Conceptualization, measurement, and nomological validity. Journal of Business Research, 57: 805-812.

White, R. 1959. Motivation reconsidered: The concept of competence. Psychological Review, 66: 297-333.

Wilder, K. M., Collier, J. E., \& Barnes, D. C. 2014. Tailoring to customers' needs: Understanding how to promote an adaptive service experience with frontline employees. Journal of Service Research, 17: 446-459.

Wright, P. M., Gardner, T. M., Moynihan, L. M., \& Allen, M. R. 2005. The relationship between HR practices and firm performance: Examining causal order. Personnel Psychology 58: 409-446.

Zhang, X., \& Bartol, K. M. 2010. Linking empowering leadership and employee creativity: The influence of psychological empowerment, intrinsic motivation, and creative process engagement. Academy of Management Journal, 53: 107-128.

Zhou, J., \& Hoever, I. J. 2014. Research on workplace creativity: A review and redirection. Annual Review of Organizational Psychology and Organizational Behavior, 1: 333-359.

Zyphur, M. J., Kaplan, S. A., \& Christian, M. S. 2008. Assumptions of cross-level measurement and structural invariance in the analysis of multilevel data: Problems and solutions. Group Dynamics: Theory, Research, and Practice, 12: 127-140. 